\title{
Creatinine Fluctuation Has a Greater Effect than the Formula to Estimate Glomerular Filtration Rate on the Prevalence of Chronic Kidney Disease
}

\author{
Simon de Lusignan ${ }^{\mathrm{a}}$ Charles Tomson $^{\mathrm{b}}$ Kevin Harris ${ }^{\mathrm{c}}$ Jeremy van Vlymen ${ }^{\mathrm{a}}$ \\ Hugh Gallagher $^{d}$ \\ a Division of Community Health Sciences, St. George's, University of London, London, b Department of \\ Renal Medicine, Southmead Hospital, Bristol, ' John Walls Renal Unit, Leicester General Hospital, \\ University Hospitals of Leicester, Leicester, and ${ }^{\mathrm{d}}$ SW Thames Renal Unit, St. Helier Hospital, Carshalton, UK
}

\section{Key Words}

Chronic kidney disease $\cdot$ Creatinine fluctuation •

Glomerular filtration rate

\begin{abstract}
Background/Aims: Cases of chronic kidney disease (CKD) are defined by the estimated glomerular filtration rate (eGFR), calculated using the Modified Diet in Renal Disease (MDRD) or, more recently, the CKD Epidemiology Collaboration (CKD-EPI) formula. This study set out to promote a systematic approach to reporting CKD prevalence. Design, Setting, Participants and Measurements: The study explores the impact of the way in which eGFR is calculated on the prevalence of CKD. We took into account whether including (1) ethnicity, (2) using a single eGFR, (3) using more than 1 eGFR value or (4) using the CKD-EPI formula affected the estimates of prevalence. Sample: Of 930,997 registered patients, $36 \%(332,891)$ have their eGFR defined $(63 \%$ of those aged $50-74$ years, $81 \%>75$ years). Results: The prevalence of stage 3-5 CKD is $5.41 \%(n=50,331)$. (1) Not including ethnicity data the prevalence would be $5.49 \%$, (2) just using the latest eGFR $6.4 \%$, (3) excluding intermediary values $5.55 \%$ and (4) using the CKD-EPI equation $4.8 \%$. All changes in eGFR ( $t$ test) and the proportion with CKD ( $\chi^{2}$ test) were significant $(p<0.001)$. Using serum-creatinine-calculated eGFR instead of laboratory data reduced the prevalence of stage 3-5 CKD by around $0.01 \%$. Sixty-six percent of people with stage 3-5
\end{abstract}

disease have cardiovascular disease and $4.0 \%$ significant proteinuria using the MDRD formula; the corresponding figures using CKD-EPI are 74 and 4.6\%. Conclusions: A standardised approach to reporting case finding would allow a better comparison of prevalence estimates. Using a single eGFR tends to inflate the reported prevalence of CKD by ignoring creatinine fluctuation; this effect is greater than the difference between MDRD and CKD-EPI.

Copyright $\odot 2010$ S. Karger AG, Basel

\section{Introduction}

Accurate case definition is essential for the reliable and accurate reporting of the prevalence of a condition. The classic components of case definitions are time, place and person [1]. Last's Dictionary of Epidemiology [2] defines a case as:

A person in the population or study group identified as having the particular disease, health disorder or condition under investigation. A variety of criteria may be used to identify cases... the epidemiologic definition of a case is not necessarily the same as the ordinary clinical definition.

Without a precise case definition, it is more difficult to measure trends, report unusual clusters or other occurrences, or measure the effectiveness of an intervention.

\section{KARGER}

Fax +41613061234 E-Mail karger@karger.ch www.karger.com (c) 2010 S. Karger AG, Basel

$1660-2110 / 11 / 1173-0213 \$ 38.00 / 0$

Accessible online at:

www.karger.com/nec
Simon de Lusignan

Division of Community Health Sciences, Hunter Wing

St. George's University of London

London SW17 0RE (UK)

Tel. +44 208725 5661, Fax +44 208725 3584, E-Mail slusigna@ sgul.ac.uk 
Cases of chronic kidney disease (CKD) have been defined using a simple formula to estimate glomerular filtration rate (eGFR), the 4-variable Modified Diet in Renal Disease (MDRD) equation:

\section{eGFR $\left(\mathrm{ml} / \mathrm{min} / 1.73 \mathrm{~m}^{2}\right)=$}

$186.3 \times\left(\right.$ serum creatinine $\left./ 88.40^{-1.154}\right) \times\left(\right.$ age $\left.^{-0.203}\right) \cdot 0.742$

(if female) and $\cdot 1.21$ (if African-American) [3].

The Kidney Disease Quality Outcomes Group requires 2 eGFR measurements for a formal diagnosis of CKD:

Kidney damage for $\geq 3$ months ...

... or GFR $<60 \mathrm{ml} / \mathrm{min} / 1.73 \mathrm{~m}^{2}$ for $\geq 3$ months with or without kidney damage [4].

Hence the CKD case definition takes into account: ethnicity; a 'constant'; 2 GFR readings, and, for stage 1 and 2 disease, evidence of kidney damage. More recently a new formula - the Chronic Kidney Disease Epidemiology Collaboration (CKD-EPI) - has been introduced. The CKD-EPI formula displays less bias and more precision than the MDRD formula, especially where the eGFR is $>60 \mathrm{ml} / \mathrm{min} / 1.73 \mathrm{~m}^{2}$ [5].

There are differences in the way this case definition is implemented. The UK's National Guidance translates African American into African Caribbean [6], sometimes further modified into black ethnicity [7]. The constant (186.3) is not valid for all laboratory analyses [8], and so the eGFR provided by the laboratory, which includes an assay-specific correction, is more reliable than an eGFR calculated from a serum creatinine (SCr) value using the standard formula. Some studies have only used 1 eGFR, including those used to model the UK's national prevalence of CKD [9-11] and to estimate the cost-effectiveness of the implementation of national guidelines on CKD management [12]. Guidance from the National Institute of Health and Clinical Excellence also emphasises the need for chronicity in diagnosis (and implies that interim values of eGFR should be taken into account), stating that for a diagnosis of CKD, the eGFR should be $<60$ $\mathrm{ml} / \mathrm{min} / 1.73 \mathrm{~m}^{2}$ or there should be markers of kidney damage 'on at least 2 occasions for $\geq 3$ months' [6].

A further complication is that some chemical pathology laboratories do not report eGFR across the entire range [13] but stop at eGFR $>60 \mathrm{ml} / \mathrm{min} / 1.73 \mathrm{~m}^{2}$. Finally, routine clinical data used for the epidemiological study of CKD may contain SCr readings, with or without laboratory-derived eGFR recordings, and contain 1 or more readings of either SCr or eGFR recorded at irregular and inconsistent intervals.
We carried out this study as we started a large cluster randomised study of quality improvement interventions in CKD [14] to see if the source or type of data used to define CKD cases made any significant difference to the estimated prevalence so that we could make allowance in interpreting the results of our trial if the frequency of testing or proportion of laboratory-calculated eGFR values changed over the 2 years of the study.

\section{Method}

Overview

Our 'reference' method for defining a case of CKD stage 3-5, with which other diagnostic strategies were compared, was to require that the patient had had 2 measurements of eGFR, reported by the laboratory [and therefore using the isotope-dilution-massspectrometry (IDMS)-aligned MDRD formula], both less than 60 $\mathrm{ml} / \mathrm{min} / 1.73 \mathrm{~m}^{2}$ and without any intervening measurements of GFR that were greater than $60 \mathrm{ml} / \mathrm{min} / 1.73 \mathrm{~m}^{2}$.

We developed a method of categorising the data sources used to define eGFR.

We compared the effects on mean eGFR, the proportion in each class of CKD, and the prevalence when we took into account:

(1) Variation in the way that black ethnicity is incorporated into estimating eGFR;

(2) use of a single eGFR reading;

(3) comparing laboratory-derived and investigator-calculated eGFR values;

(4) including interim values in CKD definition (such that the documentation of 2 eGFR readings $\leq 60 \mathrm{ml} / \mathrm{min} / 1.73 \mathrm{~m}^{2}>3$ months apart would not result in a diagnosis of stage $3-5 \mathrm{CKD}$ if there was an intervening eGFR $>60 \mathrm{ml} / \mathrm{min} / 1.73 \mathrm{~m}^{2}$ ).

Finally, we conducted a sensitivity analysis by comparing our Quality Improvement in CKD (QICKD) study case-finding method using the MDRD formula with the CKD-EPI formula, and, in the absence of any gold standard comparison of the accuracy of the GFR measure, we instead looked at the proportion of people with cardiovascular co-morbidities and proteinuria in the 2 groups.

\section{Subjects and Settings}

We initially report the prevalence of CKD from the QICKD study. The study is spread across 129 practices in England - drawn from London and the south-east, Leicester, Birmingham and Cambridge. UK practices have a registration system; one person can only register with one practice. Individuals have a unique identifier (NHS number), and general practice is largely computerised. A combination of technical advances, such as computerised links to pathology laboratories, and pay-for-performance quality improvement interventions have improved record quality [15]. Pseudo-anonymised routine clinical data were extracted using Morbidity Information Query and Export Syntax [16], the standard data export tool used in the UK. These data were recorded as part of routine care, and eGFR is reported nationally when renal function tests are requested. Renal function tests tend to be requested in UK primary care as part of chronic disease management and as part of the routine work-up of people who present unwell [17]. de Lusignan/Tomson/Harris/ van Vlymen/Gallagher 
Reporting the Prevalence of CKD and the Source of the Data

We report the crude and standardised prevalence of CKD in the QICKD study population and the different sources of these data.

There are 5 different possible combinations of laboratory-reported and investigator-calculated eGFR.

We have categorised them as follows:

Category A: eGFR defined as the higher of 2 laboratory-derived eGFR measurements at least 3 months apart (including noting the laboratory assay method and if the laboratory is part of a quality assurance process);

Category B: eGFR defined as the higher of 1 laboratory-derived eGFR and 1 investigator-calculated eGFR from SCr, at least 3 months apart;

Category C: eGFR defined as the higher of 2 investigator-calculated eGFR at least 3 months apart;

Category D: eGFR defined from a single laboratory-derived eGFR;

Category E: eGFR calculated from a single SCr assessment.

\section{Effect on Prevalence of Including Black Ethnicity}

We report the difference in prevalence when we include known black or Afro-Caribbean ethnicity. Ethnicity in primary care is usually self-reported but may be recorded by practice staff or clinicians. Ethnicity data are coded using different hierarchies and with varying levels of specificity [18]. We extract data from each of these code hierarchies and have developed analysis methods which mean we can capture the most specific code recorded for the patient. As no formal systems exist, we have developed our own mapping between the hierarchies [19]. We explore the effect of applying the correction factor to people with black ethnicity and to those with African Caribbean ethnicity.

\section{Comparing Case Finding Using a Single or Pair of eGFR}

Reading

We compared the effect of using the single latest eGFR for those people (categories $\mathrm{A}-\mathrm{C}$ ) for whom we have 2 readings at least 3 months apart.

\section{Correcting for the Laboratory Assay by Comparing Paired}

\section{Laboratory-and Investigator-Calculated eGFR}

Most creatinine assays are now standardised in the UK using IDMS as the gold standard, through the National External Quality Assurance Scheme [8]. A specific IDMS-traceable version of the MDRD formula is then applied:

$\mathrm{eGFR}\left(\mathrm{ml} / \mathrm{min} / 1.73 \mathrm{~m}^{2}\right)=175 \times\left(\right.$ serum creatinine $\left./ 88.40^{-1.154}\right)$ can).

$\times\left(\right.$ age $\left.^{-0.203}\right) \cdot 0.742$ (if female) and $\cdot 1.21$ (if African-Ameri-

This uses 175 as the constant rather than the 186.3 used in the original MDRD formula.

We explored the effect on prevalence and class of CKD by comparing paired laboratory-derived eGFR values with investigator-calculated eGFR for those patients who have both recorded (category A). We did this by identifying the pathology laboratory that the individual practice used, and then contacting that laboratory to see if they used an IDMS-aligned assay or not. We applied the appropriate formula where the IDMS-traceable assay was used. We made the assumption that the results at a given practice came from their local laboratory. There is no flag within individual results to enable any more specific analysis.

Effect of Case Selection on CKD

Prevalence
The Effect of Using Interim Values on the Prevalence of CKD

Routine data contain values at irregular intervals, and when identifying 2 eGFR readings at least 3 months apart there are inevitably varying numbers of interim values. We set up a sorting application to look at up to 10 interim readings, substituting the interim value if higher than the first or last defining value.

Sensitivity Analysis

Fluctuation in creatinine will change eGFR, and description of change in eGFR should provide face validity that the changes described in the class of eGFR are plausible. We describe the change in eGFR between the minimum and maximum values within a single year, over 2 years and over 5 years.

We conducted a sensitivity analysis in 2 further ways. Firstly, we looked at the number of people with CKD found with the CKD-EPI formula, using paired creatinine measurements where available, and taking into account laboratory assay and interim readings where available, to give as like-with-like comparison as possible with the QICKD study method. Secondly, we explored the proportion of cardiovascular co-morbidity and proteinuria found by each method of estimating eGFR; in the absence of a gold standard, we presumed that a better case finding formula would include a higher proportion of people in higher-risk groups. We did this by creating a variable for any existing cardiovascular disease, including hypertension and diabetes. We created 2 proteinuria variables: 'significant' and 'stick test' proteinuria. Significant proteinuria was defined in the UK National Guidance; we included all quantitative tests (24-hour tests, and total protein- and albumin-to-creatinine ratios, but not dipstick tests) and also taking into account the different thresholds for diabetes. Significant proteinuria was defined in people without diabetes as any of: an albumin:creatinine ratio of $>30 \mathrm{mg} / \mathrm{mmol}$, a total protein:creatinine ratio of $>50 \mathrm{mg} / \mathrm{mmol}$, a 24 -hour protein excretion of $>0.5 \mathrm{~g}$; in people with diabetes, we defined significant proteinuria as an albumin:creatinine ratio $>2.5$ or $3.5 \mathrm{mg} / \mathrm{mmol}$ in males and females, respectively. We also created a stick-test-positive proteinuria variable; tests of $1+$ or more were considered positive; trace was counted as a negative test.

The Model for Categorising and Reporting Prevalence of CKD from Routine Data

We developed a reporting form based on the 5 categories described at the start of this method to describe the source of eGFR measures used to define CKD prevalence. The details of the logical model are shown in the appendix and the pilot reporting form shown below.

The QICKD study [14] received ethical approval from the UK National Research Ethics Service in November 2008.

\section{Results}

\section{Sample}

The sample size is approximately 1 million $(\mathrm{n}=$ 930,997) patients with an age-sex distribution similar to the national average [20]. There are some small differences: a small excess of men over women (50.1:49.9\%) and a greater proportion of working age people (fig. 1). The 
Fig. 1. Age and sex distribution of the study population $(n=930,997)$; lines show the standard English population (National Statistics, UK census 2001).

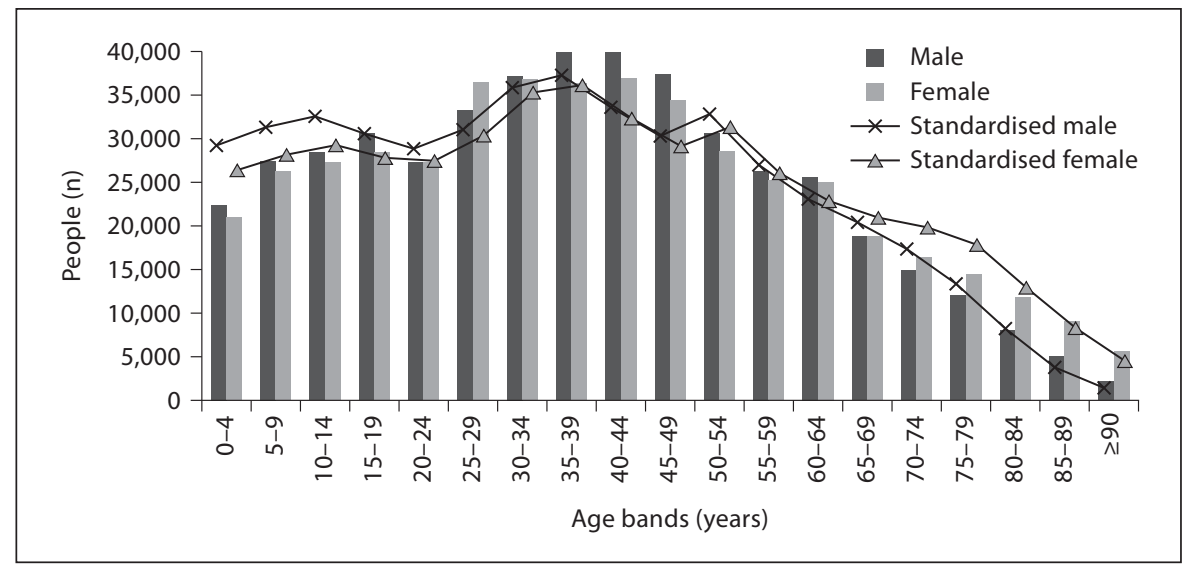

Fig. 2. Age and sex distribution of the population with stage $3-5$ CKD $(n=50,331)$; lines show the standard English population (National Statistics, UK census 2001).

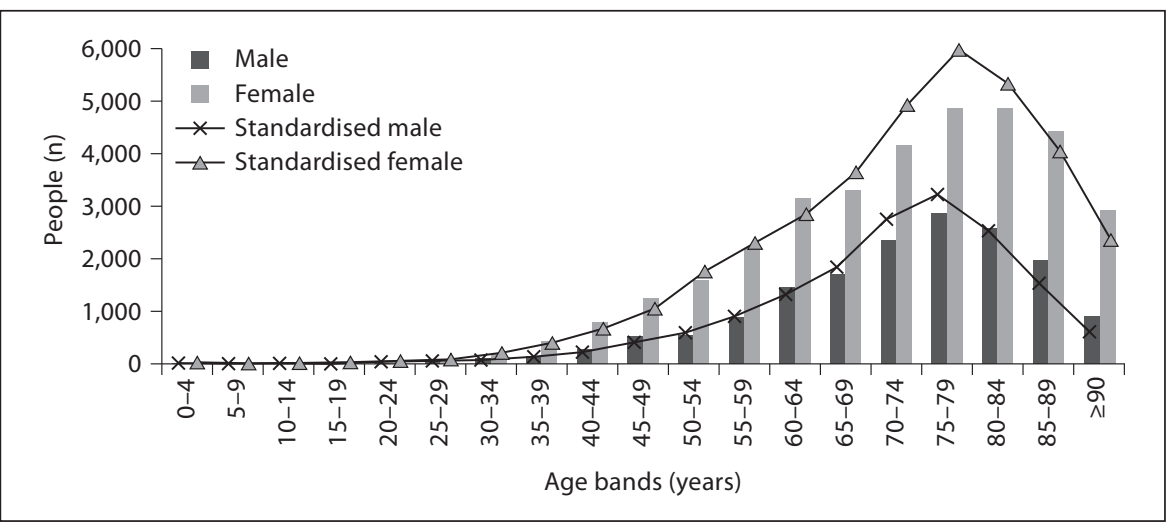

people with stage 3-5 CKD are older with many more females than males (fig. 2).

\section{Prevalence of Stage 3-5 CKD Using the MDRD \\ Formula}

The crude prevalence of stage 3-5 CKD in our sample was $5.41 \%$, with $7.34 \%$ in females and $3.48 \%$ in males. The standardised prevalence was the same to 2 decimal places. The proportion of males with stage 3-5 CKD increased as renal function declined. The ratio of women to men is for stage $3 a, 2.2: 1$; in stages $3 b, 1.9: 1$; in stage 4 , 1.4:1, and roughly equal proportions in stage 5 (table 1 ).

$36.8 \%$ of the population had an SCr or eGFR measure though the proportion was greater with increased age. $80.9 \%$ of people over 75 and $63 \%$ between 50 and 74 years have an SCr or eGFR record.

\section{Source of eGFR in the QICKD Trial Baseline Data}

Over three quarters $(76.1 \%)$ of people with stage 3-5 CKD have at least 2 laboratory readings (QICKD categories A-C) and nearly $90 \%$ of those with stage $3 \mathrm{~b}$ and stage 4 disease (table 2,3). The lower rate of eGFR recording in people with normal renal function may reflect the practice of some laboratories not to report eGFR $\geq 60 \mathrm{ml} /$ $\mathrm{min} / 1.73 \mathrm{~m}^{2}$.

The Effect of Black Ethnicity on Prevalence of CKD

Ethnicity was reported for just under half of the population (46.4\%). A higher proportion of people with their creatinine measured had their ethnicity recorded (50.6\%); the proportion was slightly higher for those with stage 3-5 CKD, where $51.8 \%$ had their ethnicity recorded.

People with black ethnicity recorded were approximately half as likely to have stage $3-5 \mathrm{CKD}$ as those without black ethnicity recorded (8.6 vs. $15.4 \% ; \chi^{2} \mathrm{p}<0.001$ ). However, they were equally likely to have stage 4 and more likely to have stage 5 disease. Incorporating black ethnicity into the equation reduced the number of people with stage $3-5$ CKD by $1.5 \%$; the changes that occurred were all into the next highest class of CKD.

Contrastingly, people with African Caribbean ethnicity have an equal or increased prevalence of CKD. African Caribbean ethnicity is recorded for a subset of around half the black population $(51.1 \%, \mathrm{n}=7,552 / 14,766)$, and unlike 
Table 1. Proportion of the population by gender with a creatinine measurement and with an eGFR by stage of CKD

\begin{tabular}{lrrr}
\hline CKD class/SCr & \multicolumn{1}{l}{ Female } & Male & \multicolumn{1}{c}{ Total } \\
\hline No SCr measurement & $279,280(46.7)$ & $318,826(53.3)$ & 598,106 \\
Normal eGFR & $34,400(50.5)$ & $33,751(49.5)$ & 68,151 \\
Mildly impaired eGFR & $117,164(54.6)$ & $97,245(45.4)$ & 214,409 \\
Stage 3a & $28,879(68.6)$ & $13,206(31.4)$ & 42,085 \\
Stage 3b & $4,349(64.9)$ & $2,349(35.1)$ & 6,698 \\
Stage 4 & $693(59.1)$ & $479(40.9)$ & 1,172 \\
Stage 5 & $192(51.1)$ & $184(48.9)$ & 376 \\
Stage 3-5 CKD & $34,113(67.8)$ & $16,218(32.2)$ & 50,331 \\
All with SCr measurement & $185,677(55.8)$ & $147,214(44.2)$ & 332,891 \\
\hline Total & $464,957(49.9)$ & $466,040(50.1)$ & 930,997 \\
\hline
\end{tabular}

Results are patient numbers, with percentages in parentheses.

Table 2. Source of eGFR value based on the category of eGFR calculation

\begin{tabular}{|c|c|c|c|c|c|c|c|}
\hline & \multicolumn{3}{|c|}{$\begin{array}{l}\text { eGFR readings based on at least } 2 \text { measurements } \\
\text { (where an intermediary value changes eGFR) }\end{array}$} & \multirow[t]{2}{*}{ Subtotal } & \multicolumn{2}{|c|}{$\begin{array}{l}\text { eGFR based on a single } \\
\text { measurement of eGFR }\end{array}$} & \multirow[t]{2}{*}{ Total } \\
\hline & $\begin{array}{l}\text { A } \\
\text { (2 lab. eGFR) }\end{array}$ & $\begin{array}{l}\text { B } \\
\text { (1 lab., } 1 \\
\text { SCr eGFR) }\end{array}$ & $\begin{array}{l}\text { C } \\
\text { (2 SCr eGFR) }\end{array}$ & & $\begin{array}{l}\text { D } \\
(1 \text { lab. eGFR) }\end{array}$ & $\begin{array}{l}\text { E } \\
(1 \text { SCr eGFR })\end{array}$ & \\
\hline Normal eGFR & $2,528(3.7)$ & $4,575(6.7)$ & $23,970(35.2)$ & $31,073(45.6)$ & $2,293(3.4)$ & $34,785(51.0)$ & 68,151 \\
\hline Mildly impaired eGFR & $30,651(14.3)$ & $21,045(9.8)$ & $78,052(36.4)$ & $129,748(60.5)$ & $14,919(7.0)$ & $69,742(32.5)$ & 214,409 \\
\hline Subtotal & $33,179(11.7)$ & $25,620(9.1)$ & $102,022(36.1)$ & $160,821(56.9)$ & $17,212(6.1)$ & $104,527(37.0)$ & 282,560 \\
\hline Stage $3 a$ & $15,750(37.4)$ & $5,685(13.5)$ & $9,595(22.8)$ & $31,030(73.7)$ & $2,915(6.9)$ & $8,140(19.3)$ & 42,085 \\
\hline Stage $3 b$ & $4,010(59.9)$ & 509 (7.6) & $1,402(20.9)$ & $5,921(88.4)$ & $374(5.6)$ & $403(6.0)$ & 6,698 \\
\hline Stage 4 & $729(62.2)$ & $98(8.4)$ & $210(17.9)$ & $1,037(88.5)$ & $85(7.3)$ & $50(4.3)$ & 1,172 \\
\hline Stage 5 & $168(44.7)$ & $54(14.4)$ & $77(20.5)$ & $299(79.5)$ & $43(11.4)$ & $34(9.0)$ & 376 \\
\hline Subtotal stages 3-5 & $20,657(41.0)$ & $6,346(12.6)$ & $11,284(22.4)$ & $38,287(76.1)$ & $3,417(6.8)$ & $8,627(17.1)$ & 50,331 \\
\hline Total & $53,836(16.2)$ & $31,966(9.6)$ & $113,306(34.0)$ & $199,108(59.8)$ & $20,629(6.2)$ & $113,154(34.0)$ & 332,891 \\
\hline
\end{tabular}

The percentage in parentheses gives the proportion of each source for a given class of CKD. lab. = Laboratory.

other blacks in general they have an approximately equal prevalence of stage 3-5 CKD (14.7\% of those with an eGFR record compared with $15.1 \%)$. Though, as with black ethnicity there were proportionately more cases with stage 4 and 5 disease $(8.8 \%$ of the people with stage 5 disease are of African Caribbean ethnicity and 3.1\% stage 4 compared with 0.3 and $0.1 \%$ in the rest of the population).

\section{Using a Single Latest eGFR}

We compared the single latest eGFR with our more exhaustive process of taking into account paired and interim values. Using just latest values gives a mean eGFR of $78.5 \mathrm{ml} / \mathrm{min} / 1.73 \mathrm{~m}^{2}$, whereas using all the available paired eGFR produces a lower mean eGFR of $77.4 \mathrm{ml} /$ $\min / 1.73 \mathrm{~m}^{2}$. As the mean is just over 1 standard deviation $\left(\mathrm{SD}=14 \mathrm{ml} / \mathrm{min} / 1.73 \mathrm{~m}^{2}\right)$ the cutoff for stage 3 , any change has a large effect on the number of individuals in each class of CKD. The proportion with stage 3 disease increases from $14.7 \%(\mathrm{n}=48,783)$ to $17.2 \%(\mathrm{n}=57,405)$; this change is statistically significant $\left(\chi^{2} \mathrm{p}<0.001\right)$. Using the single latest eGFR value changes the prevalence of stage 3-5 CKD from 5.4 to $6.4 \%$.

\section{Comparing Investigator- and Laboratory-Calculated eGFR}

We compared the effect of using 2 laboratory-derived eGFR measures with using investigator-calculated eGFR. We compared the 53,836 people in 'category A' who had 
Table 3. The proportion of intermediary values that change the eGFR for paired eGFR data sources (category A-C): eGFR readings based on at least 2 measurements

\begin{tabular}{|c|c|c|c|c|c|c|c|c|}
\hline & $\begin{array}{l}\text { A } \\
\text { (2 lab. eGFR) }\end{array}$ & $\begin{array}{l}\text { A int. } \\
\text { (2 lab. eGFR } \\
\text { adj. by } \\
\text { interim) }\end{array}$ & $\begin{array}{l}\text { B } \\
\text { (1 lab., } 1 \\
\text { SCr eGFR) }\end{array}$ & $\begin{array}{l}\text { B int. } \\
\text { (1 lab, } 1 \mathrm{SCr} \\
\text { eGFR adj. by } \\
\text { interim) }\end{array}$ & $\begin{array}{l}\text { C } \\
\text { (2 SCr eGFR) }\end{array}$ & $\begin{array}{l}\text { C int. } \\
\text { ( } 2 \text { SCr } \\
\text { eGFR adj. } \\
\text { by interim) }\end{array}$ & $\begin{array}{l}\text { Total for } \\
\text { categories } \\
\text { A-C }\end{array}$ & $\begin{array}{l}\text { Total } \\
\text { interim- } \\
\text { adj. } \\
\text { eGFR }\end{array}$ \\
\hline Normal eGFR & $2,441(3.6)$ & $87(0.13)$ & $4,220(6.2)$ & $355(0.52)$ & $23,221(34.1)$ & $749(1.1)$ & $31,073(45.6)$ & $1,191(3.8)$ \\
\hline Mildly impaired eGFR & $29,687(13.8)$ & $964(0.45)$ & $19,970(9.3)$ & $1,075(0.50)$ & $76,198(35.5)$ & $1,854(0.9)$ & $129,748(60.5)$ & $3,893(3.0)$ \\
\hline Subtotal & $32,128(11.4)$ & $1,051(0.37)$ & $24,190(8.6)$ & $1,430(0.51)$ & $99,419(35.2)$ & $2,603(0.9)$ & $160,821(56.9)$ & $5,084(3.2)$ \\
\hline Stage $3 a$ & $15,054(35.8)$ & $696(1.65)$ & $5,367(12.8)$ & $318(0.76)$ & $9,295(22.1)$ & $300(0.7)$ & $31,030(73.7)$ & $1,314(4.2)$ \\
\hline Stage $3 b$ & $3,756(56.1)$ & $254(3.79)$ & $476(7.1)$ & $33(0.49)$ & $1,331(19.9)$ & $71(1.1)$ & $5,921(88.4)$ & $358(6.0)$ \\
\hline Stage 4 & $682(58.2)$ & $47(4.01)$ & $91(7.8)$ & $7(0.60)$ & $188(16.0)$ & $22(1.9)$ & $1,037(88.5)$ & $76(7.3)$ \\
\hline Stage 5 & $160(42.6)$ & $8(2.13)$ & $53(14.1)$ & $1(0.27)$ & $75(19.9)$ & $2(0.5)$ & $299(79.5)$ & $11(3.7)$ \\
\hline Subtotal stages 3-5 & $19,652(39.0)$ & $1,005(2.00)$ & $5,987(11.9)$ & $359(0.71)$ & $10,889(21.6)$ & $395(0.8)$ & $38,287(76.1)$ & $1,759(4.6)$ \\
\hline Total & $51,780(15.6)$ & $2,056(0.62)$ & $30,177(9.1)$ & $1,789(0.54)$ & $110,308(33.1)$ & $2,998(0.9)$ & $199,108(59.8)$ & $6,843(3.4)$ \\
\hline
\end{tabular}

Int. = Where an intermediary value changes eGFR; lab. = laboratory; adj. = adjusted. Results are patient numbers, with percentages in parentheses.

Table 4. The effect on class of CKD of using SCr-calculated eGFR compared with using laboratory-corrected eGFR

\begin{tabular}{|c|c|c|c|c|}
\hline & \multirow{2}{*}{$\begin{array}{l}\text { QICKD category A } \\
\text { (2 laboratory-derived } \\
\text { eGFR) }\end{array}$} & \multicolumn{3}{|c|}{$\begin{array}{l}\text { Class of CKD from SCr } \\
\text { (eGFR based on } 2 \text { SCr readings) }\end{array}$} \\
\hline & & total & moves & change, $\%$ \\
\hline Normal eGFR & $2,528(4.7)$ & $3,603(6.7)$ & 1,075 & 42.5 \\
\hline Mildly impaired eGFR & $30,651(56.9)$ & $30,120(55.9)$ & -531 & -1.7 \\
\hline Subtotal & $33,179(61.6)$ & $33,723(62.6)$ & 544 & 1.6 \\
\hline Stage $3 \mathrm{a}$ & $15,750(29.3)$ & $14,887(27.7)$ & -863 & -5.5 \\
\hline Stage $3 b$ & $4,010(7.4)$ & $4,335(8.1)$ & 325 & 8.1 \\
\hline Stage 4 & $729(1.4)$ & $772(1.4)$ & 43 & 5.9 \\
\hline Stage 5 & $168(0.3)$ & $119(0.2)$ & -49 & -29.2 \\
\hline Subtotal stages 3-5 & $20,657(38.4)$ & $20,113(37.4)$ & -544 & -2.6 \\
\hline Total & $53,836(100.0)$ & $53,836(100.0)$ & 5,269 & 9.8 \\
\hline
\end{tabular}

Figures in parentheses indicate percentages.

both laboratory-derived eGFR and 2 SCr measures. Again there was only a small difference in the mean eGFR $\left(66.7 \mathrm{ml} / \mathrm{min} / 1.73 \mathrm{~m}^{2}\right.$ for laboratory measures compared with $66.8 \mathrm{ml} / \mathrm{min} / 1.73 \mathrm{~m}^{2}$ in those derived from SCr). However, this small difference is again statistically significant (paired-sample t test $\mathrm{p}<0.001$ ) and results in around $2 \%$ more people in the $\mathrm{SCr}$ group being classified as having a normal or mildly impaired eGFR rather than having stage 3-5 CKD (table 4). Not using laboratory results has a much smaller effect on the population prevalence than other factors, probably around
$0.01 \%$ reduction, if we assume that we have identified most people with CKD.

The Effect of Taking into Account Interim eGFR Values

Taking into account any interim values for eGFR only increased eGFR in $3.4 \%$ of cases; however, the effect was greatest with declining eGFR (table 3 ): $4.2 \%$ in stage $3 a$; $6 \%$ in stage $3 b ; 7.3 \%$ in stage $4\left(\chi^{2} p<0.001\right)$; we did not include stage 5 because of small numbers.

Overall, inclusion of interim values reduced the number of people with stage 3-5 CKD by $2.4 \%$. Most of those 
Table 5. Effect on class of CKD of applying different case-finding strategies

\begin{tabular}{|c|c|c|c|c|c|c|c|c|c|}
\hline & \multirow{2}{*}{$\begin{array}{l}\text { QICKD case } \\
\text { definition: } \\
\text { class of CKD }\end{array}$} & \multicolumn{2}{|c|}{ Ethnicity not included } & \multicolumn{2}{|c|}{ No interim eGFR included } & \multicolumn{2}{|l|}{ Latest eGFR only } & \multicolumn{2}{|c|}{ CKD-EPI prevalence } \\
\hline & & $\begin{array}{l}\text { class of } \\
\text { CKD }\end{array}$ & $\begin{array}{l}\text { moved } \\
\text { class }\end{array}$ & $\begin{array}{l}\text { class of } \\
\text { CKD }\end{array}$ & $\begin{array}{l}\text { moved } \\
\text { class }\end{array}$ & $\begin{array}{l}\text { class of } \\
\text { CKD }\end{array}$ & $\begin{array}{l}\text { moved } \\
\text { class }\end{array}$ & $\begin{array}{l}\text { class of } \\
\text { CKD }\end{array}$ & $\begin{array}{l}\text { moved } \\
\text { class }\end{array}$ \\
\hline Normal eGFR & $68,151(20.5)$ & $65,730(19.7)$ & $-2,421(-3.7)$ & $65,213(19.6)$ & $-2,938(-4.5)$ & $67,086(20.2)$ & $-1,065(-1.6)$ & $107,823(11.6)$ & $39,736(36.9)$ \\
\hline Mildly impaired eGFR & $214,409(64.4)$ & $216,092(64.9)$ & $1,683(0.8)$ & $216,045(64.9)$ & $1,636(0.8)$ & $20,6146(61.9)$ & $-8,263(-3.9)$ & $180,113(19.3)$ & $-33,878(-18.8)$ \\
\hline Subtotal & $282,560(84.9)$ & $281,822(84.7)$ & $-738(-0.3)$ & $281,258(84.5)$ & $-1,302(-0.5)$ & $273,232(82.1)$ & $-9,328(-3.3)$ & $287,936(86.7)$ & $5,858(2.0)$ \\
\hline Stage 3a & $42,085(12.6)$ & $42,770(12.8)$ & $685(1.6)$ & $43,170(13.0)$ & $1,085(2.5)$ & $48,589(14.6)$ & $6,504(15.5)$ & $2,698(3.5)$ & $-9,291(-28.4)$ \\
\hline Stage $3 b$ & $6,698(2.0)$ & $6,743(2.0)$ & $45(0.7)$ & $6,873(2.1)$ & $175(2.5)$ & $8,816(2.6)$ & $2,118(31.6)$ & $9,377(1)$ & $2,711(28.9)$ \\
\hline Stage 4 & $1,172(0.4)$ & $1,177(0.4)$ & $5(0.4)$ & $1,206(0.4)$ & $34(2.8)$ & $1,773(0.5)$ & $601(51.3)$ & $1,815(0.2)$ & $647(35.6)$ \\
\hline Stage 5 & $376(0.1)$ & $379(0.1)$ & $3(0.8)$ & $384(0.1)$ & $8(2.1)$ & $481(0.1)$ & $105(27.9)$ & $438(0)$ & $75(17.1)$ \\
\hline Subtotal stages 3-5 & $50,331(15.1)$ & $51,069(15.3)$ & $738(1.4)$ & $51,633(15.5)$ & $1,302(2.5)$ & $59,659(17.9)$ & $9,328(18.5)$ & $44,328(13.3)$ & $-5,858(-13.2)$ \\
\hline Total & $332,891(100.0)$ & $332,891(100)$ & $6,446(1.9)$ & $332,891(100.0)$ & 4,490 (1.9) & $332,891(100.0)$ & $27,679(8.3)$ & $332,264(100)$ & $81,398(24.5)$ \\
\hline $\begin{array}{l}\text { Stage } 3-5 \text { population } \\
\text { prevalence }\end{array}$ & & 51,069 & (5.49) & 51,633 & $1,302(5.55)$ & 59,659 & $9,328(6.41)$ & $(4.80)$ & $-5,858$ \\
\hline
\end{tabular}

Results are patient numbers, with percentages in parentheses.

Table 6. Sensitivity analysis: proportion of cases with cardiovascular co-morbidity identified by different case-finding methods

\begin{tabular}{|c|c|c|c|c|c|c|c|c|c|c|}
\hline & \multicolumn{2}{|c|}{$\begin{array}{l}\text { QICKD case finding } \\
\text { method }\end{array}$} & \multicolumn{2}{|c|}{$\begin{array}{l}\text { Not taking into } \\
\text { account black ethnicity }\end{array}$} & \multicolumn{2}{|c|}{$\begin{array}{l}\text { Not taking into account } \\
\text { interim values }\end{array}$} & \multicolumn{2}{|c|}{$\begin{array}{l}\text { Using latest } \\
\text { creatinine/eGFR }\end{array}$} & \multicolumn{2}{|c|}{$\begin{array}{l}\text { CKD-EPI - allowance } \\
\text { for SCr fluctuation as in } \\
\text { QICKD }\end{array}$} \\
\hline & $\begin{array}{l}\text { cases } \\
\text { with valid } \\
\text { eGFR, } n\end{array}$ & CVD, valid n & $\begin{array}{l}\text { cases } \\
\text { with valid } \\
\text { eGFR, } n\end{array}$ & CVD, valid n & $\begin{array}{l}\text { cases } \\
\text { with valid } \\
\text { eGFR, } \mathrm{n}\end{array}$ & CVD, valid n & $\begin{array}{l}\text { cases } \\
\text { with valid } \\
\text { eGFR, } n\end{array}$ & CVD, valid n & $\begin{array}{l}\text { cases } \\
\text { with valid } \\
\text { eGFR, } n\end{array}$ & CVD, valid n \\
\hline Normal eGF & 68,151 & $15,100(22.16)$ & 65,730 & $14,272(21.7)$ & 65,213 & $13,966(21.42)$ & 67,086 & $15,136(22.56)$ & 180,113 & $69,306(38.48)$ \\
\hline Mildly impaired & 214,409 & $78,170(36.46)$ & 216,092 & $78,597(36.4)$ & 216,045 & $78,455(36.31)$ & 206,146 & $72,643(35.24)$ & 107,823 & $24,002(22.26)$ \\
\hline Subtotal & 282,560 & 93,270 (33.01) & 281,822 & $92,869(33.0)$ & 281,258 & $92,421(32.86)$ & 273,232 & $87,779(32.13)$ & 287,936 & $93,308(32.41)$ \\
\hline Stage 3a & 42,085 & 25,887 (61.51) & 42,770 & $26,249(61.4)$ & 43,170 & 26,544 (61.49) & 48,589 & $28,987(59.66)$ & 32,698 & $22,677(69.35)$ \\
\hline Stage $3 b$ & 6,698 & $5,808(86.71)$ & 6,743 & $5,839(86.6)$ & 6,873 & $5,958(86.69)$ & 8,816 & $7,566(85.82)$ & 9,377 & $8,120(86.59)$ \\
\hline Stage 4 & 1,172 & $1,064(90.78)$ & 1,177 & $1,069(90.8)$ & 1,206 & $1,098(91.04)$ & 1,773 & $1,596(90.02)$ & 1,815 & $1,661(91.52)$ \\
\hline Stage 5 & 376 & $333(88.56)$ & 379 & $336(88.7)$ & 384 & $341(88.80)$ & 481 & $434(90.23)$ & 438 & $397(90.64)$ \\
\hline Subtotal & 50,331 & $33,092(65.75)$ & 51,069 & $33,493(65.6)$ & 51,633 & $33,941(65.74)$ & 59,659 & $38,583(64.67)$ & 44,328 & $32,855(74.12)$ \\
\hline Total & 332,891 & $126,362(37.96)$ & 332,891 & $126,362(38.0)$ & 332,891 & $126,362(37.96)$ & 332,891 & $126,362(37.96)$ & 332,264 & $126,163(37.97)$ \\
\hline
\end{tabular}

Figures in parentheses indicate percentages; $\mathrm{CVD}=\mathrm{Co}$-morbidity with 1 or more cardiovascular diseases and/or diabetes mellitus.

who changed class only moved up 1 class (table 5). However, 2 people with stage 5 disease moved to stage $3 \mathrm{a}, 4$ from stage $3 b$ to mildly impaired eGFR and 5 from stage 3a to normal renal function. Although taking into account interim values has a small effect on the prevalence of stage 3-5 CKD, it can have a profound influence on individual cases.

\section{Sensitivity Analysis}

The mean change in eGFR between minimum and readings taken in the year of the study was $-0.03 \mathrm{ml} /$ $\mathrm{min} / 1.73 \mathrm{~m}^{2}$ (SD $12.7 \mathrm{ml} / \mathrm{min} / 1.73 \mathrm{~m}^{2}$; we use a minus sign to signify an overall rise in eGFR); the change over 2 years was a mean fall of $1.29 \mathrm{ml} / \mathrm{min} / 1.73 \mathrm{~m}^{2}$ (SD $14.5 \mathrm{ml} /$ $\mathrm{min} / 1.73 \mathrm{~m}^{2}$ ) and over 5 years a decline in $2.37 \mathrm{ml} / \mathrm{min} / 1.73$ $\mathrm{m}^{2}\left(\mathrm{SD} 16.8 \mathrm{ml} / \mathrm{min} / 1.73 \mathrm{~m}^{2}\right)$. The widening SD represents the bimodal distribution of the change in eGFR. Over 1 year slightly more (of the over 33,000) paired eGFR values change upwards compared with down; over 2 years the peak for decline is larger than for increase, and over 5 years the changes are further exaggerated. We note how just under a third $(31 \%, \mathrm{n}=16,587)$ of people have a decline over $5 \mathrm{ml} / \mathrm{min} / 1.73 \mathrm{~m}^{2}$ in 1 year and more just over a fifth (22\%, $\mathrm{n}=4,2960)$ a decline of over $10 \mathrm{ml} / \mathrm{min} / 1.73 \mathrm{~m}^{2}$ in 5 years. 
Table 7. Sensitivity analysis: proportion of cases identified with significant proteinuria identified by different case-finding methods

\begin{tabular}{|c|c|c|c|c|c|c|c|c|c|c|}
\hline & \multicolumn{2}{|c|}{$\begin{array}{l}\text { QICKD case-finding } \\
\text { method }\end{array}$} & \multicolumn{2}{|c|}{$\begin{array}{l}\text { Not taking into account } \\
\text { black ethnicity }\end{array}$} & \multicolumn{2}{|c|}{$\begin{array}{l}\text { Not taking into account } \\
\text { interim values }\end{array}$} & \multicolumn{2}{|c|}{$\begin{array}{l}\text { Using latest } \\
\text { creatinine/eGFR }\end{array}$} & \multicolumn{2}{|c|}{$\begin{array}{l}\text { CKD-EPI - allowance } \\
\text { for SCr fluctuation as in } \\
\text { QICKD }\end{array}$} \\
\hline & $\begin{array}{l}\text { cases } \\
\text { with valid } \\
\text { eGFR, } \mathrm{n}\end{array}$ & $\begin{array}{l}\text { significant } \\
\text { proteinuria, } \\
\text { valid } \mathrm{n}\end{array}$ & $\begin{array}{l}\text { cases } \\
\text { with valid } \\
\text { eGFR, } n\end{array}$ & $\begin{array}{l}\text { significant } \\
\text { proteinuria, } \\
\text { valid } \mathrm{n}\end{array}$ & $\begin{array}{l}\text { cases } \\
\text { with valid } \\
\text { eGFR, } n\end{array}$ & $\begin{array}{l}\text { significant } \\
\text { proteinuria, } \\
\text { valid } \mathrm{n}\end{array}$ & $\begin{array}{l}\text { cases } \\
\text { with valid } \\
\text { eGFR, } \mathrm{n}\end{array}$ & $\begin{array}{l}\text { significant } \\
\text { proteinuria, } \\
\text { valid } n\end{array}$ & $\begin{array}{l}\text { cases } \\
\text { with valid } \\
\text { eGFR, } n\end{array}$ & $\begin{array}{l}\text { significant } \\
\text { proteinuria, } \\
\text { valid } \mathrm{n}\end{array}$ \\
\hline Normal eGFR & 68,151 & $633(0.93)$ & 65,730 & $596(0.9)$ & 65,213 & $574(0.88)$ & 67,086 & $642(0.96)$ & 180,113 & $926(0.51)$ \\
\hline Mildly impaired & 214,409 & $2,359(1.1)$ & 216,092 & $2,369(1.1)$ & 216,045 & 2,365 (1.09) & 206,146 & $2,153(1.04)$ & 107,823 & $2,027(1.88)$ \\
\hline Subtotal & 282,560 & $2,992(1.06)$ & 281,822 & $2,965(1.1)$ & 281,258 & $2,939(1.04)$ & 273,232 & $2,795(1.02)$ & 287,936 & $2,953(1.03)$ \\
\hline Stage $3 \mathrm{a}$ & 42,085 & $1,153(2.74)$ & 42,770 & $1,175(2.7)$ & 43,170 & $1,178(2.73)$ & 48,589 & $1,133(2.33)$ & 32,698 & $943(2.88)$ \\
\hline Stage $3 b$ & 6,698 & $581(8.67)$ & 6,743 & $585(8.7)$ & 6,873 & $600(8.73)$ & 8,816 & $710(8.05)$ & 9,377 & $721(7.69)$ \\
\hline Stage 4 & 1,172 & $193(16.47)$ & 1,177 & $192(16.3)$ & 1,206 & 199 (16.5) & 1,773 & $264(14.89)$ & 1,815 & $271(14.93)$ \\
\hline Stage 5 & 376 & $68(18.09)$ & 379 & $70(18.5)$ & 384 & $71(18.49)$ & 481 & $85(17.67)$ & 438 & $84(19.18)$ \\
\hline Subtotal & 50,331 & 1,995 (3.96) & 51,069 & $2,022(4)$ & 51,633 & $2,048(3.97)$ & 59,659 & $2,192(3.67)$ & 44,328 & $2,019(4.55)$ \\
\hline Total & 332,891 & $4,987(1.5)$ & 332,891 & $4,987(1.5)$ & 332,891 & $4,987(1.5)$ & 332,891 & $4,987(1.5)$ & 332,264 & $4,972(1.5)$ \\
\hline
\end{tabular}

Figures in parentheses indicate percentages. Significant proteinuria assessed by a positive quantitative test.

We found that using the CKD-EPI formula the prevalence of stage 3-5 CKD was $4.8 \%$. This is lower than that reported using the QICKD study case-finding approach but was a smaller difference than that between using paired or a single creatinine reading (table 5).

Just over two thirds $(67.5 \%)$ of the people with stage 3-5 CKD using the QICKD study case-finding method had co-morbid cardiovascular disease; it was only $1 \%$ less where 1 creatinine reading was used. However, nearly three quarters $(74.1 \%)$ of the people with stage $3-5$ disease identified with the CKD-EPI formula have 1 or more cardiovascular diseases (table 6).

The same pattern is present for proteinuria. Mainly due to low rates of recording in non-diabetics, the prevalence of significant proteinuria in stage 3-5 disease is $3.96 \%$. This proportion falls very slightly as elements of the MDRD formula are dropped. However, CKD-EPI appears to be more specific with a rate of $4.55 \%$ (table 7 ). Stick tests show the same pattern; however, there are around one-and-a-half times as many positive results $10.13 \%$ of people with stage $3-5$ have proteinuria when the CKD-EPI formula is used and 9.24\% of those identified using MDRD (table 8).

\section{Summary of Effects of Including Ethnicity, Interim,}

Just Latest and Comparing Paired eGFR Values on

Prevalence of $C K D$

We found a prevalence of $5.41 \%$ for stage 3-5 CKD. However, had we used a different approach we would report a different prevalence: (1) without including ethnic- ity data prevalence would be $5.49 \%$; (2) just using the latest value it would be $6.4 \%$; (3) not including interim eGFR values would give 5.55\%; (4) had we used CKD-EPI and taken the same steps to smooth creatinine, the prevalence would be $4.80 \%$ (table 5). Using eGFR calculated from SCr instead of laboratory values reduced the cases of stage $3-5$ CKD by $2.6 \%$, potentially marginally lowering CKD prevalence to around $5.4 \%$ (table 4 ).

\section{Discussion}

\section{Principal Findings}

Changes in estimated prevalence due to fluctuation in creatinine level (fig. 3) are greater than those from using CKD-EPI instead of the MDRD formula, though CKDEPI identifies a much higher proportion of people classified as having stage 3-5 CKD and having cardiovascular co-morbidity and proteinuria than the proportion classified as CKD 3-5 using the MDRD formula.

How investigators define cases of CKD will change their reported prevalence. A system of explicit reporting of the source of the data used to identify cases of CKD may enable better comparisons to be drawn between studies. Excluding ethnicity or interim values, or just using the latest routine clinical reading, leads to an overestimation of the population prevalence of stage 3-5 CKD. Using SCr to calculate eGFR may underestimate the prevalence of CKD, but only by a very small amount if the formula is adjusted for assay type. 
Table 8. Sensitivity analysis: proportion of cases identified with proteinuria found by dipstick (at least $1+$ positive) identified by different case-finding methods

\begin{tabular}{|c|c|c|c|c|c|c|c|c|c|c|}
\hline & \multicolumn{2}{|c|}{$\begin{array}{l}\text { QICKD case-finding } \\
\text { method }\end{array}$} & \multicolumn{2}{|c|}{$\begin{array}{l}\text { Not taking into account } \\
\text { black ethnicity }\end{array}$} & \multicolumn{2}{|c|}{$\begin{array}{l}\text { Not taking into account } \\
\text { interim values }\end{array}$} & \multicolumn{2}{|c|}{$\begin{array}{l}\text { Using latest } \\
\text { creatinine/eGFR }\end{array}$} & \multicolumn{2}{|c|}{$\begin{array}{l}\text { CKD-EPI - allowance } \\
\text { for SCr fluctuation as in } \\
\text { QICKD }\end{array}$} \\
\hline & $\begin{array}{l}\text { cases } \\
\text { with valid } \\
\text { eGFR, n }\end{array}$ & $\begin{array}{l}\text { significant } \\
\text { proteinuria, } \\
\text { valid n }\end{array}$ & $\begin{array}{l}\text { cases } \\
\text { with valid } \\
\text { eGFR, n }\end{array}$ & $\begin{array}{l}\text { significant } \\
\text { proteinuria, } \\
\text { valid } \mathrm{n}\end{array}$ & $\begin{array}{l}\text { cases } \\
\text { with valid } \\
\text { eGFR, } \mathrm{n}\end{array}$ & $\begin{array}{l}\text { significant } \\
\text { proteinuria, } \\
\text { valid } \mathrm{n}\end{array}$ & $\begin{array}{l}\text { cases } \\
\text { with valid } \\
\text { eGFR, } \mathrm{n}\end{array}$ & $\begin{array}{l}\text { significant } \\
\text { proteinuria, } \\
\text { valid } \mathrm{n}\end{array}$ & $\begin{array}{l}\text { cases } \\
\text { with valid } \\
\text { eGFR, n }\end{array}$ & $\begin{array}{l}\text { significant } \\
\text { proteinuria, } \\
\text { valid } \mathrm{n}\end{array}$ \\
\hline Normal eGFR & 68,151 & $10,914(16.01)$ & 65,730 & $10,989(16.72)$ & 65,213 & $10,985(16.84)$ & 67,086 & $10,666(15.90)$ & 180,113 & $5,034(2.79)$ \\
\hline Mildly impaired & 214,409 & $3,161(1.47)$ & 216,092 & $3,025(1.40)$ & 216,045 & $2,978(1.38)$ & 206,146 & $3,162(1.53)$ & 107,823 & $9,163(8.50)$ \\
\hline Subtotal & 282,560 & 14,075 (4.98) & 281,822 & $14,014(4.97)$ & 281,258 & $13,963(4.96)$ & 273,232 & $13,828(5.06)$ & 287,936 & $14,197(4.93)$ \\
\hline Stage $3 a$ & 42,085 & $3,307(7.86)$ & 42,770 & $3,357(7.85)$ & 43,170 & $3,381(7.83)$ & 48,589 & $3,477(7.16)$ & 32,698 & $2,746(8.40)$ \\
\hline Stage $3 b$ & 6,698 & $949(14.17)$ & 6,743 & 957 (14.19) & 6,873 & $977(14.22)$ & 8,816 & $1,015(11.51)$ & 9,377 & $1,219(13.00)$ \\
\hline Stage 4 & 1,172 & $275(23.46)$ & 1,177 & $277(23.53)$ & 1,206 & $283(23.47)$ & 1,773 & $302(17.03)$ & 1,815 & $378(20.83)$ \\
\hline Stage 5 & 376 & $120(31.91)$ & 379 & $121(31.93)$ & 384 & $122(31.77)$ & 481 & $104(21.62)$ & 438 & $146(33.33)$ \\
\hline Subtotal & 50,331 & $4,651(9.24)$ & 51,069 & $4,712(9.23)$ & 51,633 & $4,763(9.22)$ & 59,659 & $4,898(8.21)$ & 44,328 & $4,489(10.13)$ \\
\hline Total & 332,891 & $18,726(5.6)$ & 332,891 & $18,726(5.6)$ & 332,891 & $18,726(5.6)$ & 332,891 & $18,726(5.6)$ & 332,264 & $18,686(5.6)$ \\
\hline
\end{tabular}

Figures in parentheses indicate percentages. Significant proteinuria assessed by a positive quantitative test.

We also note that many patients with CKD have a substantial fluctuation in their eGFR, often exceeding the limits in decline of $5 \mathrm{ml} / \mathrm{min} / 1.73 \mathrm{~m}^{2}$ over 1 year and 10 $\mathrm{ml} / \mathrm{min} / 1.73 \mathrm{~m}^{2}$ over 5 years set out in the National Guidelines [6].

\section{Implications of the Findings}

Both CKD-EPI and the MDRD formula power SCr similarly and make a similar allowance for black ethnicity. Thus, whichever form of equation is used, fluctuation in creatinine and adjusting for ethnicity will have a similar influence. Relying on a single eGFR reading with no allowance for fluctuation has a greater influence on prevalence than using CKD-EPI instead of MDRD.

It is possible that previous studies have overestimated the prevalence of CKD. The New Opportunities for Early Renal Intervention by Computerised Assessment (NEOERICA) study used a single reading of $\mathrm{SCr}$ and reported a prevalence of $8.2 \%$ [10] compared with $5.4 \%$ reported here. If we had used a single value of SCr to calculate eGFR, it would have increased our prevalence to $6.4 \%$; if we presume the effects of ethnicity and interim values are additive, it would further increase the prevalence to $6.7 \%$. The distribution of the NEOERICA practices were similar but had more centres in the north of England, which may also have contributed to the difference [21]. The Third National Health and Nutritional Examination Survey also appears to have used a single reading of cre- atinine; our data would suggest that this may have overestimated the prevalence of CKD [22].

Calculators, including our own in-house version, should consider limiting their description of black ethnicity to African American or African Caribbean [1,23].

Using this system we propose the prevalence of CKD would be reported providing the following data for the population as a whole and for people with stage $3-5 \mathrm{CKD}$ : (1) the denominator or population size of the study; (2) creatinine/eGFR recording; (3) if ethnicity recording is available, the level of recording and how it is coded within the clinical record [18, 24]; (4) the proportion of eGFR originating from each category, and (5) if interim values are taken into consideration.

Using the QICKD categories when reporting studies based on routine data would more readily allow different studies to be compared and the influence of different approaches to defining a case of CKD to be more easily compared.

Further investigation is needed to explore whether the fluctuation in eGFR we report over 1 and 5 years represents normal variation or a missed pathological process. If it is the latter, revision of guidance may be needed [6]. However, clinical judgement is important in both interpreting the significance of an eGFR reading as well as any decline. The existence as well as a decline of eGFR in a 30 -year-old male may be much more significant than the potentially explainable fluctuation in an elderly person with an intercurrent illness. 
Fig. 3. Fluctuation between minimum and maximum eGFR over 1, 2 and 5 years; the lines indicate a decline of over 5 and $10 \mathrm{ml} /$ $\mathrm{min} / 1.73 \mathrm{~m}^{2}$ in eGFR.

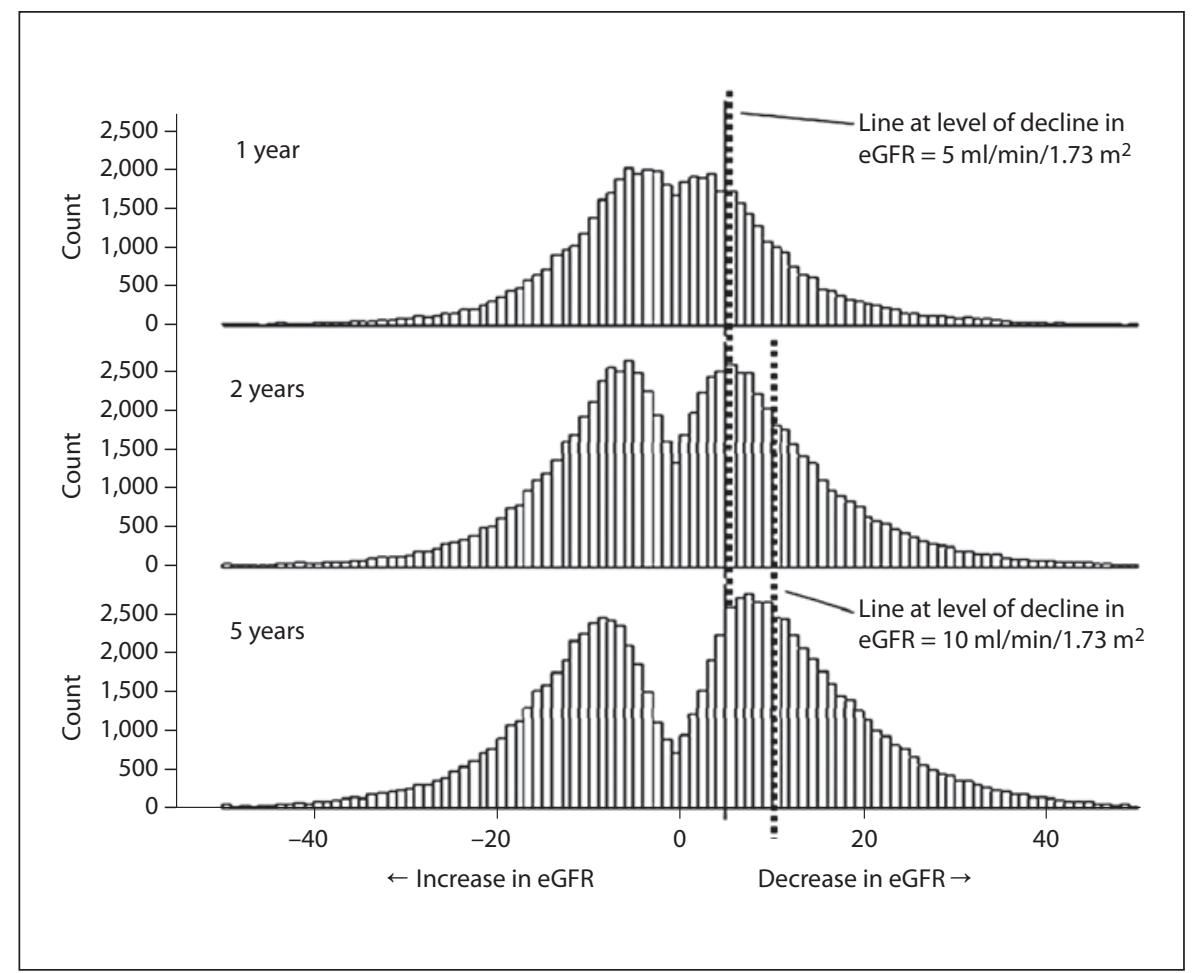

\section{Limitations of the Method}

The opportunities and limitations of working with routinely collected data are well known [25], and it is possible that earlier work from the UK overestimated the prevalence and therefore the cost-consequence of this disease [26]. Our first methodology paper did not take into account laboratory corrections or fluctuation in creatinine [9]; subsequent work to estimate prevalence did but still relied on a high proportion of single readings [10]. We have progressed but our data set still has limitations and does not allow us to accurately model the impact of these different influences on the recorded prevalence of CKD. However, it does form a basis for developing such a model and making comparisons between different studies.

We are not directly criticising NEOERICA (S.L. and J.V. are co-authors); it was a study reflecting the state of the art at the time [10]. We were not aware how much difference fluctuation in SCr might make to CKD prevalence, though other factors may also contribute to the difference in prevalence, especially the higher proportion of people in QICKD who have an SCr measurement of $35 \%$ in this current study versus $30 \%$ in NEOERICA.

Although proposed as a new formula [3], CKD-EPI has not been widely introduced into clinical practice.
CKD-EPI does reduce the estimated prevalence of CKD, particularly stage $3 \mathrm{a}$, and it is the reduction of the size of this group which appears to increase the association of CKD with cardiovascular disease and proteinuria. There is controversy as to whether patients with CKD stage $3 \mathrm{a}$, especially elderly females, have a pathological process or whether this is part of normal ageing [27].

\section{Comparison with the Literature}

We could not identify the literature where similar comparisons have been made. More recent guidance [6] has stressed the importance of SCr being measured after avoiding large protein meals [28] and that the specimen should be analysed within $12 \mathrm{~h}[29,30]$. However, although this may reduce some of the variation between creatinine measures, it is unlikely to account for all the variation seen. Fluctuation is unlikely to be due to laboratory error as there is stringent quality control in the UK using IDMS-traceable assays [31].

\section{Call for Further Research}

Two GFR measurements from a complete population would allow a perfect model to be constructed. We currently presume that we have identified most cases of $\mathrm{CKD}$, and that we can extrapolate where there is missing 
data. Additionally, we may be seeing regression to the mean, as where eGFR is 'normal' no further tests may be done, whereas if eGFR is low the test may be repeated.

Definitions of accelerated decline in eGFR may need review or to be based on more than 2 readings.

\section{Conclusions}

Reports of CKD prevalence should report how they have allowed for fluctuation in creatinine as it may have a greater influence on reported prevalence than moving from MDRD reported cases of eGFR to using CKD-EPI. Studies based on single readings may significantly overestimate the prevalence, and study authors are recommended to consider using the QICKD categories (see appendix below) to show the origins of their data. Failure to report how fluctuations in SCr have been taken into account may lead to greater differences in reported prevalence than using a different formula.

\section{Appendix: Model to Create Variables to Differentiate Categories of Source of eGFR}

\section{Logical model and variable labels used:}

Principles for defining 'master eGFR' to assign stages of CKD:

(1) For all source data display as separate variables for 'code' (in the UK the Read code, but it might be an ICD or SNOMED term in another health system), 'date' (the date when the data were recorded in the electronic patient record) and 'value' (its numerical value); this enables derived variables to be traced back to source

(2) Take latest laboratory-calculated eGFR and label this eGFR_L1 (use derived eGFR if there is no laboratory eGFR)

(3) Count back 90 days and find the next laboratory-calculated eGFR = eGFR_L190 (or eGFR derived from SCr if there is no laboratory eGFR)

(4) Look at all eGFR recordings between these dates (only laboratory-issued eGFR count if we have 2 laboratory-derived eGFR) and pick the highest of these; the highest value in between could be called eGFR_ L1_90_int

If this eGFR is greater than eGFR_L1 or eGFR_L1 90 , then use this to define the stage of CKD

Laboratory-calculated eGFR interim values can trump laboratory values, whereas SCr interim values cannot

It does not matter how many interim values there are (eGFR_L190_int1, eGFR_L190_int2, eGFR_L190_int3 etc.), we use the highest

(5) eGFR results and SCr must have different dates

Detailed logical model - create the following variables:

(1) Extract code, date and value for latest laboratory-defined eGFR (latest laboratory-defined eGFR variable: eGFR_L1)

(2) Code data value for penultimate laboratory-defined eGFR - where it is more than 90 days before (penultimate laboratory-defined eGFR variable: eGFR_L1_90)

(3) Code data value for highest interim laboratory-defined eGFR where interim if any between L1 and L1_90 eGFR >eGFR L1 or L1_90 (interim laboratory-defined eGFR variable: eGFR_L1_90_int)

(4) Code data value for latest creatinine (latest creatinine variable: 44J3-L1)

(5) Calculated eGFR from latest creatinine (eGFR_calc_value_1)

Effect of Case Selection on CKD

Prevalence
(6) Code data value for penultimate $\mathrm{SCr}$ - where it is more than 90 days before (penultimate SCr44J3-L1_90)

(7) Calculated eGFR from latest penultimate creatinine at least 90 days before (eGFR_calc_value_L1_90)

(8) Code data value for highest interim SCr where interim SCr $>44 J 3$ _L1 or $>44$ J_L1_90; for this highest creatinine, calculate an eGFR (variable: eGFR_calc_value_L1_90_int)

(9) Master eGFR - 1 eGFR code, data and value based on the following hierarchy:

a Two laboratory eGFR $>90$ days apart; take the higher value; calculate from columns 1 and 2

b If not present or a higher reading between - Two lab results $>90$ days apart raised by a higher interim value Calculate from columns: (1) OR (2) and (3)

c If not present - take the higher value of 1 laboratory eGFR and 1 SCrcalculated eGFR $>90$ days apart; calculate from columns 1 and 5

d If not present or a higher reading between -1 laboratory eGFR and $1 \mathrm{SCr}$-calculated eGFR $>90$ days apart raised by a higher interim value; calculate from columns 1 or 5 and 8

e If not present - take the higher value of $2 \mathrm{SCr}$-calculated eGFR $>90$ days apart; calculate from columns 5 and 7

$\mathrm{f}$ If not present - take the higher value of $2 \mathrm{SCr}$-calculated eGFR $>90$ days apart raised by a higher interim value; calculate from columns 5 or 7 and 8

g If not present - 1 laboratory eGFR; calculate from column 1

$\mathrm{h}$ If not present - $1 \mathrm{SCr}$-calculated eGFR; calculate from column 5 N.B. Only 1 value appears depending on its origin; the date is the date of the eGFR contributing to the calculation

(10) Basis of master eGFR:

a Category $A^{\text {int. }}-2$ laboratory eGFR $>90$ days apart

b Category A - 2 laboratory results $>90$ days apart raised by a higher interim value

c Category $B^{\text {int. }}-1$ laboratory eGFR and 1 SCr-calculated eGFR $>90$ days apart

d Category B - 1 laboratory eGFR and 1 SCr-calculated eGFR $>90$ days apart raised by a higher interim value

e Category $\mathrm{C}^{\text {int. }}-2 \mathrm{SCr}$-calculated eGFR $>90$ days apart

f Category $\mathrm{C}-2 \mathrm{SCr}$-calculated $\mathrm{eGFR}>90$ days apart raised by a higher interim value

g Category D - 1 laboratory eGFR

h Category E - 1 SCr-calculated eGFR

i Only 1 category number appears in this column

(11) Date of most recent (latest) eGFR or SCr used; date of column 1 or column 5

(12) Date of penultimate (L1_90) eGFR or SCr used or interim higher 'trumping' value; date of column 2 or 3 or 7 or $8 \ldots$

\section{Acknowledgements}

The QICKD study is funded by the Health Foundation, with additional funding from the Edith Murphy Trust. The study is run by a team drawn from Kidney Research UK, University Hospitals of Leicester, and St. George's, University of London, and the participating general practices. We thank Mehdi-Ward for expert advice in database management. 


\section{References}

1 Pan American Health Organisation - World Health Organisation: Norms and standards in epidemiology: case definitions. Epidemiological Bulletin 1999, vol 20. http://www. paho.org/english/sha/be991norms.htm.

2 Last J: A Dictionary of Epidemiology, ed 4. Oxford, Oxford University Press, 2001, p 21.

3 Levey AS, Bosch JP, Lewis JB, Greene T, Rogers N, Roth D: A more accurate method to estimate glomerular filtration rate from serum creatinine: a new prediction equation. Modification of Diet in Renal Disease Study Group. Ann Intern Med 1999;130:461-470.

4 National Kidney Foundation, Kidney Disease Outcomes Quality Initiative (NKF-KDOQI): NKF-aKDOQI guidelines. 4. Definition and classification of stages of chronic kidney disease. http://www.kidney.org/professionals/ kdoqi/guidelines_ckd/p4_class_g1.htm.

5 Levey AS, Stevens LA, Schmid CH, Zhang YL, Castro AF 3rd, Feldman HI, Kusek JW, Eggers P, Van Lente F, Greene T, Coresh J: CKD-EPI (Chronic Kidney Disease Epidemiology Collaboration): a new equation to estimate glomerular filtration rate. Ann Intern Med 2009;150:604-612.

6 National Institute for Health and Clinical Excellence (NICE): Guidelines for the management of chronic kidney disease in adults. http://www.nice.org.uk/Guidance/CG73.

7 Renal Association: UK CKD eGuide. http:// www.renal.org/eGFRcalc/GFR.pl.

8 Lamb EJ, Wood J, Stowe HJ, O'Riordan SE, Webb MC, Dalton RN: Susceptibility of glomerular filtration rate estimations to variations in creatinine methodology: a study in older patients. Ann Clin Biochem 2005;42: 11-18.

9 de Lusignan S, Chan T, Stevens P, O'Donoghue D, Hague N, Dzregah B, van Vlymen J, Walker M, Hilton S: Identifying patients with chronic kidney disease from general practice computer records. Fam Pract 2005; 22:234-241.

10 Stevens PE, O’Donoghue DJ, de Lusignan S, van Vlymen J, Klebe B, Middleton R, Hague N, New J, Farmer CK: Chronic kidney disease management in the United Kingdom: NEOERICA project results. Kidney Int 2007; 72:92-99.

11 APHO (Association of Public Health Observatories): CKD estimates - Neoerica 210209. http://www.apho.org.uk/resource/item. aspx?RID $=63798$.
12 Klebe B, Irving J, Stevens PE, O'Donoghue DJ, de Lusignan S, Cooley R, Hobbs H, Lamb EJ, John I, Middleton R, New J, Farmer CK: The cost of implementing UK guidelines for the management of chronic kidney disease. Nephrol Dial Transplant 2007;22:2504-2512.

13 Anavekar N, Bais R, Carney S, Davidson J, Eris J, Gallagher M, Johnson D, Jones G, Sikaris K, Lonergan M, Ludlow M, Mackie J, Mathew T, May S, McBride G, Meerkin M, Peake M, Power D, Snelling P, Voss D, Walker R, Australian Creatinine Consensus Working Group: Chronic kidney disease and automatic reporting of estimated glomerular filtration rate: a position statement. Clin Biochem Rev 2005;26:81-86.

14 de Lusignan S, Gallagher H, Chan T, Thomas $\mathrm{N}$, van Vlymen J, Nation M, Jain N, Tahir A, du Bois E, Crinson I, Hague N, Reid F, Harris, K: The QICKD study protocol: a cluster randomised trial to compare quality improvement interventions to lower systolic $\mathrm{BP}$ in chronic kidney disease $(\mathrm{CKD})$ in primary care. Implement Sci 2009;4:39. DOI: 10.1186/1748-5908-4-39.

15 de Lusignan S, Chan T: The development of primary care information technology in the United Kingdom. J Ambul Care Manage 2008;31:201-210.

16 NHS Connecting for Health: MIQUEST morbidity information and export syntax. http://www.connectingforhealth.nhs.uk/ systemsandservices/data/miquest.

17 Klebe B, Farmer C, Cooley R, de Lusignan S, Middleton R, O’Donoghue D, New J, Stevens $\mathrm{P}$ : Kidney disease management in UK primary care: guidelines, incentives and information technology. Fam Pract 2007;24:330-335.

18 Kumarapeli P, Stepaniuk R, de Lusignan S, Williams R, Rowlands G: Ethnicity recording in general practice computer systems. J Public Health (Oxf) 2006;28:283-287.

19 Kumarapeli P, de Lusignan S: Mapping between primary care ethnicity hierarchies. Primary Care Electronic Library. http:// www.pcel.info/ethnicity/.

20 National Statistics: Census 2001 - United Kingdom population. http://www.statistics. gov.uk/census2001/pop2001/united_kingdom.asp.
21 Doran T, Drever F, Whitehead M: Is there a north-south divide in social class inequalities in health in Great Britain? Cross-sectional study using data from the 2001 census. BMJ 2004;328:1043-1045.

22 Coresh J, Astor BC, Greene T, Eknoyan G, Levey AS: Prevalence of chronic kidney disease and decreased kidney function in the adult US population: Third National Health and Nutrition Examination Survey. Am J Kidney Dis 2003;41:1-12.

23 Kumarapeli P, de Lusignan S, Robinson J: Online resources for chronic kidney disease (CKD) for primary care. Inform Prim Care 2006;14:139-142.

24 de Lusignan S: Codes, classifications, terminologies and nomenclatures: definition, development and application in practice. Inform Prim Care 2005; 13:65-70.

25 de Lusignan S, van Weel C: The use of routinely collected computer data for research in primary care: opportunities and challenges. Fam Pract 2006;23:253-263

26 Klebe B, Irving J, Stevens PE, O’Donoghue DJ, de Lusignan S, Cooley R, Hobbs H, Lamb EJ, John I, Middleton R, New J, Farmer CK: The cost of implementing UK guidelines for the management of chronic kidney disease. Nephrol Dial Transplant 2007;22:2504-2512.

27 Roderick PJ, Atkins RJ, Smeeth L, Mylne A, Nitsch DD, Hubbard RB, Bulpitt CJ, Fletcher $\mathrm{AE}: \mathrm{CKD}$ and mortality risk in older people: a community-based population study in the United Kingdom. Am J Kidney Dis 2009;53: 950-960.

28 Preiss DJ, Godber IM, Lamb EJ, Dalton RN, Gunn IR: The influence of a cooked-meat meal on estimated glomerular filtration rate. Ann Clin Biochem 2007;44:35-42.

29 Shepherd J, Warner M, Kilpatrick E: Stability of creatinine with delayed separation of whole blood and implications for eGFR. Ann Clin Biochem 2007;44:384-387.

30 Ford L, Berg J: Delay in separating blood samples affects creatinine measurement using the Roche kinetic Jaffe method. Ann Clin Biochem 2008;45:83-87.

31 Quinn MP, Rainey A, Cairns KJ, Marshall AH, Savage G, Kee F, Peter Maxwell A, Reaney E, Fogarty DG: The practical implications of using standardized estimation equations in calculating the prevalence of chronic kidney disease. Nephrol Dial Transplant 2008;23:542-548. de Lusignan/Tomson/Harris/ van Vlymen/Gallagher 